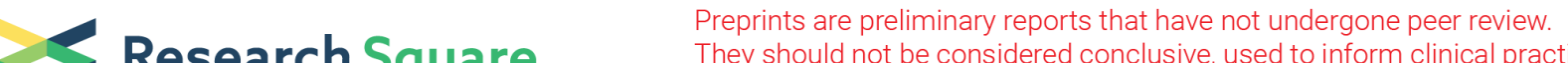 They should not be considered conclusive, used to inform clinical practice, or referenced by the media as validated information.
}

\section{Multi-Granularity Feasibility Evaluation Method of the Partial Destructive Disassembly for an End-of- Life Product}

\section{Lei Guo ( 18647159121@163.com )}

Inner Mongolia University of Technology https://orcid.org/0000-0002-1078-3462

Xiufen ZHANG

Inner Mongolia University of Technology https://orcid.org/0000-0003-2580-354X

\section{Research Article}

Keywords: Partial destructive disassembly, Multi-granularity, Failure characteristics, Disassembly entropy, Structure entropy weight method

Posted Date: February 23rd, 2021

DOl: https://doi.org/10.21203/rs.3.rs-226834/v1

License: () (1) This work is licensed under a Creative Commons Attribution 4.0 International License. Read Full License

Version of Record: A version of this preprint was published at The International Journal of Advanced Manufacturing Technology on July 22nd, 2021. See the published version at https://doi.org/10.1007/s00170-021-07673-4. 


\title{
Multi-granularity feasibility evaluation method of the partial destructive disassembly for an end-of-life product*
}

\author{
Lei Guo ${ }^{1}$ Xiufen Zhang ${ }^{1,2,3}$ \\ (1. College of Mechanical Engineering, Inner Mongolia University of Technology, Hohhot 010051 \\ Inner Mongolia, China \\ 2. College of Mechanical Engineering, Zhejiang University, Hangzhou, 310027, PR China; \\ 3. Canny Elevator Company Limited, Suzhou,215213, PR China)
}

\begin{abstract}
Partial destructive disassembly (PDD) is essential for end-of-life products to improve their automatic disassembly efficiency and reduce disassembly cost. A feasibility evaluation of the PDD is the key step to evaluate whether the PDD can be implemented. However, it has not been studied previously to our knowledge. To deal with this problem, a multi-granularity feasibility evaluation method is proposed. A multi-granularity feasibility evaluation model of the PDD was constructed based on the complex product's hierarchical structure, which not only described the evaluation indices from the product level to the component level but also presented methods and rules to quantify them. 1Thus, disassembly entropy was introduced into the target group's coarse granularity evaluation. The feasibility of the fine-grained index of the PDD for the component layer was constructed based on the product's failure characteristic. The fine-grained index was calculated by the fuzzy trigonometric function and its weighting was obtained based on the structure entropy
\end{abstract}

\footnotetext{
*Corresponding author :Lei Guo Email: 18647159121@163.com; Xiufen Zhang Email:xxff_6188@163.com

1. College of Mechanical Engineering, Inner Mongolia University of Technology, Hohhot 010051 Inner Mongolia, China.2. College of mechanical engineering, Zhejiang University, Hangzhou 310027,China.3 Canny Elevator Company Limited, Suzhou,215213, PR China
} 
weight method. Thus, the results of the evaluation were used as feedback to guide the PDD process. Finally, a Passat engine case study illustrates the feasibility and effectiveness of the method.

Keywords: Partial destructive disassembly; Multi-granularity; Failure characteristics;

Disassembly entropy; Structure entropy weight method

\section{Introduction}

Remanufacturing is an effective method to recover and reuse the residual value of end-of-life (EOL) products [1]. Disassembly is one of the key steps in remanufacturing. According to the depth of the disassembly, dismounting technology, and degree of automation, disassembly can be divided into several categories, such as the serial, parallel, partial destructive, and normal disassembly [2-6]. A reasonable remanufacturing disassembly mode can improve the mass disassembly efficiency and reduce the remanufacturing cost.

At present, the study of the partial destructive disassembly (PDD) is attracting widespread attention. PDD aims to achieve the unconventional disassembly of some connectors or low-value components by destructive means. Thus, the separation of components is realized by cutting a certain connector, which is mainly applied to non-detachable connections, such as riveting and welding [7]. Normal disassembly must bypass these connections, whereas partial destructive disassembly combines the advantages of the complete destructive and normal disassembly. Thus, the parallel partial destructive disassembly has important research significance for improving the remanufacturing disassembly efficiency.

PDD is an effective and efficient disassembly mode, which is essential for the automatic disassembly system to perform batch disassembly. It is known that the remanufacturing core often has un-disassembly connections (e.g., riveting or welding) and a structure with severe failures (e.g., corrosion or fractures). However, owing to the limitations of cost, demolition time, and environment, the feasibility of the partial destructive disassembly becomes an important problem to be solved.

\section{Literature review}

\subsection{Evaluation of product disassemblability in normal disassembly mode (NDM)}

Much work has been done in the evaluation of disassemblability, which can be divided into two categories: product level evaluation and component level evaluation. In the product level evaluation, Du et al. [8] evaluated the feasibility and effectiveness of machine tool disassembly from the technical, economic, and environmental feasibility perspectives. Suga et al. [9] used the 
disassembly entropy to evaluate the overall disassemblability of products. Sabaghi et al. [10] used the disassembly accessibility, contact surface, coupling means, and number of connections to evaluate the overall disassemblability of products. In the component level evaluation, Hander et al. [11] extracted the geometric constraint information of the product and interference in the disassembly process, established the interference and correlation matrix, and evaluated the disassembly ability using the interference information. Achillas et al. [12] took the residual life, quantity, quality, disassembly convenience, and environmental impact of parts as the evaluation indexes to obtain the global multi-criteria index by weighted evaluation and to determine the disassembly feasibility of parts. Chen et al. [13] calculated the disassembly efficiency of end-of-life products based on the fuzzy analytic hierarchy process evaluation method. On this basis, Sun et al. [14] introduced the failure rate of parts and established the comprehensive evaluation model of the failure rate and disassembly time.

\subsection{Evaluation of product disassemblability in partial destructive mode (PDM)}

Compared with feasibility evaluation of product disassemblability in NDM, the feasibility evaluation of product disassemblability in PDM has the advantages of guiding the actual disassembly process and a lower disassembly time and energy consumption. It has gradually become an active research topic for scholars. In terms of the feasibility evaluation of product disassemblability in PDM, the main index was constructed from the economy and disassembly efficiency. Song et al. [15] compared the cost of the disassembly sequence scheme between the partial disassembling mode and the normal one. Zhou [16] introduced time, cost, tools, noise, environment, and other indicators to evaluate the partial destructive disassembly sequence planning scheme and screen out the optimal disassembly sequence. Zeng et al. [17] evaluated the balance problem of a partial destructive disassembly line from the aspects of profit and energy consumption. Wang et al. [18] destroyed inexpensive parts and then evaluated the partial destructive disassembly line from the number of stations, smoothness, energy consumption, and disassembly profit.

Studies have conducted the disassembly feasibility evaluation from different perspectives. However, there is no systematic study on the feasibility evaluation system of the partial destructive disassembly for EOL products, and the indicator system is incomplete. Some scholars put forward the method of combining the whole and individual in the construction of the normal disassembly feasibility evaluation indicator, such as Zhang et al. [19], who constructed a multi-granularity of hierarchy disassemblability evaluation model from product level and design units level based on complex products' hierarchy structure. Zhu et al. [20] constructed a two-level evaluation index system from two levels: product and component. The component level index reflected the features of both current operations, and the product level reflected the previous disassembly process. Finally, the index was quantified by a Look-up Table.

\subsection{Research motivation}


To sum up, there are two main problems in the partial destructive disassembly evaluation of end-of-life products.

1. Disassembly feasibility evaluation studies focus on the evaluation of individual components and neglect the evaluation of the whole product. However, the number of product components is large, so the overall evaluation is difficult.

2. Most studies focused on the ideal disassembly feasibility analysis rather than considering the influence of the failure characteristics on the disassembly feasibility. In fact, the serious failure characteristics of the components also have an important impact on the disassemblability of the components. The current weighting methods are mainly based on the analytic hierarchy process (AHP), and thus there exists subjectivity and randomness in the evaluation results.

To address these problems, we propose a multi-granularity evaluation method for disassembly feasibility of EOL products in partial destructive mode. The remainder of this article is organized as follows. In Section 3, the multi-granularity feasibility evaluation model of a partial destructive disassembly for EOL products is proposed. Section 4 introduces the feasibility evaluation method of a partial destructive disassembly. In Section 5, the proposed model and method are validated with a case study. Concluding remarks are provided in Section 6.

\section{Multi-granularity feasibility evaluation model of partial destructive disassembly}

PDD aims to improve the disassembly efficiency by partial destructive disassembly operation under the premise of ensuring the integrity of the target component. The PDD encompasses two different disassembly methods: normal disassembly and destructive disassembly. The disassembly's direction, time, and tools of the EOL products are different with different disassembly methods. However, these factors cannot fully reflect the feasibility of the PDD of the products. Based on the complex products' hierarchy structure, this study presents a multi-granularity feasibility evaluation model (MGFEM) of the PDD for EOL products. The evaluation objects of the MGFEM are target group and components, and several evaluation indexes are constructed from target group layer and component layer, as shown in Fig. 1. 


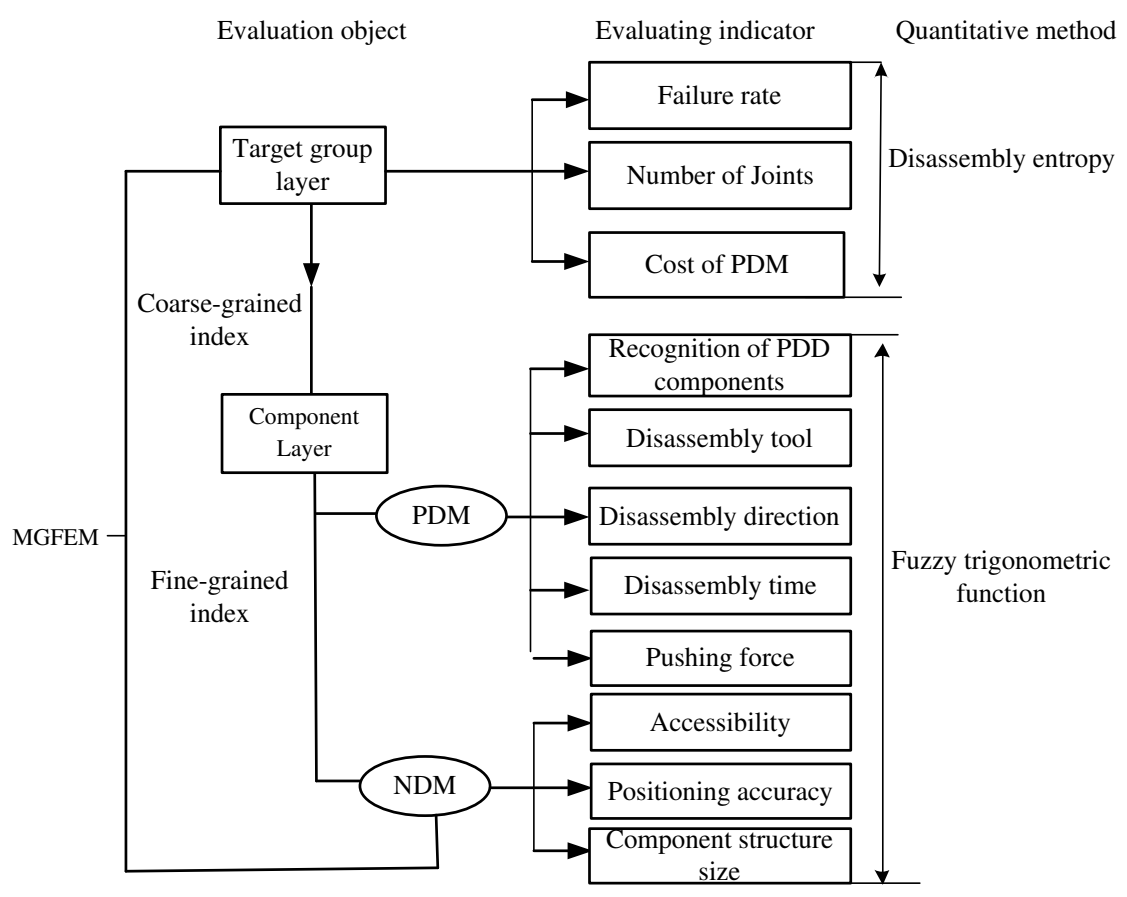

Figure 1. MGFEM of the PDD for an EOL product

\subsection{Construction of target group}

Owing to the large number of complex product components, it is difficult to evaluate them. Therefore, the target group was defined according to the component failure characteristics, which is the parts set composed of those with a high failure probability and high value parts [20] to reduce the complexity of the whole evaluation.

\subsubsection{Expression and quantification of the failure characteristics of components}

Uncertain changes have taken place in the external characteristics and internal materials of the EOL products, as shown in Table 1 . The failure type matrix $M_{1}$ was established to describe the failure type of complex product parts $v_{i}$, which can be expressed by Eq. 1 as follows:

$$
M_{1}=r_{i j}{ }_{n \times 4}^{\prime}
$$

where $r_{i j}=\left\{\begin{array}{cc}1 & \text { Parts } v_{i} \text { existence of failure type } c_{j} \\ 0 & \text { Node } v_{i} \text { no existence of failure type } c_{j} .\end{array}\right.$

In view of the uncertainty and difficulty in accurate quantification of failure characteristics of components, an expert evaluation method was used. The failure state comment set of components is $E=e_{1}, e_{2}, e_{3}, e_{4}, e_{5}$, where $e_{1}, e_{2}, e_{3}, e_{4}, e_{5}$ represents basically no failure, minor failure, general failure, moderate failure, and major cycle failure, respectively. 
Invite $N$ experts to evaluate the status of failure characteristics, and the evaluation result is $\left.A=a_{i} \quad i=1 \sim 5\right)$, where $a_{i}=\frac{n_{a_{i}}}{N}$ and it is the number of experts participating in the evaluation, and $n_{a_{i}}$ is the number of experts choosing the ${ }_{i}$ evaluation value. At this point, the eigenvalue of the failure type $c_{j}$ of component $v_{i}$ is shown in Eq. 2 .

$$
e_{i j}=E \cdot A^{T}
$$

Table 1. Part failure characteristics and recovery decision information

\begin{tabular}{|c|c|c|c|}
\hline Failure characteristic & Failure types & Failure level & Recycling decision \\
\hline Aging & $\begin{array}{l}\text { Metamorphic type ( } \\
c_{1} \text { ) }\end{array}$ & $\begin{array}{c}\text { Basically no failure }\left(e_{1}\right. \\
\text { ) }\end{array}$ & Reuse $\left(h_{1}\right)$ \\
\hline Abrasion $\quad\left(f_{2}\right)$ & Involution forms $\left(c_{2}\right)$ & $\begin{array}{c}\text { Minor failure } \\
\left.e_{2}\right)\end{array}$ & Remanufacturing $\left(h_{2}\right)$ \\
\hline Corrosion $\quad\left(f_{3}\right)$ & $\begin{array}{c}\text { Damage type }( \\
\left.c_{3}\right)\end{array}$ & $\begin{array}{c}\text { General failure } \\
\left.e_{3}\right)\end{array}$ & Material recycling $\left(h_{3}\right)$ \\
\hline Deformation $\left(f_{4}\right)$ & $\begin{array}{l}\text { Deformation type ( } \\
\qquad c_{4} \text { ) }\end{array}$ & $\begin{array}{c}\text { Moderate failure }( \\
\left.e_{4}\right)\end{array}$ & Discarding \\
\hline No failure $\quad\left(f_{5}\right)$ & $\begin{array}{l}\text { Loose type } \\
\left.c_{5}\right)\end{array}$ & $\begin{array}{c}\text { Major cycle failure } \\
\left.e_{5}\right)\end{array}$ & - \\
\hline Fracture & - & - & - \\
\hline Cavern & - & - & - \\
\hline Burn $\quad\left(f_{8}\right)$ & - & - & - \\
\hline$\ldots$ & - & - & - \\
\hline
\end{tabular}

To facilitate the overall feasibility evaluation of a product's PDD, the products are simply classified according to the failure characteristics of complex products. According to the evaluation of various failure characteristics of parts by many experts, the failure characteristics of the parts are quantified by Equations ( 1 and 2), which can be expressed by Eq. 3 .

$$
M_{2}=e_{i j} \cdot r_{i j}
$$

where $e_{i j}$ represents the characteristic value of the component failure, and $r_{i j}$ represents the failure of components type. 


\subsubsection{Quantization of coarse-grained index of target group based on disassembly entropy}

Three major factors affecting the PDD feasibility of the target group were selected: failure rate, number of joints, and cost of PDM. In this study, the disassembly entropy introduced by Suga et al. [21] is expanded. The PDD feasibility of the target group is quantitatively assessed using the disassembly entropy. The smaller the disassembly entropy is, the better the PDD feasibility of the target group is.

(1) The disassembly entropy of failure rate is

$$
S_{1}=\log _{2} N_{i} / N_{s}
$$

where $N_{i}$ indicates the total number of sub-assemblies in the target group, and $N_{s}$ is the total number of sub-assemblies with high failure probability in the target group.

(2) The disassembly entropy of the number of joints is

$$
S_{2}=\log _{2}\left[N_{i}+N_{k} / N_{k}\right]
$$

where $N_{i}$ indicates the total number of sub-assemblies in the target group, and $N_{k}$ is the total number of connectors methods $k$ (such as screws, bolted joints, welding, riveting, and non-removable connections) in the target group.

(3) The disassembly entropy of cost of PDM is

$$
S_{3}=\log _{2}\left[C_{n}+C_{m} / C_{n}\right]
$$

where $C_{n}$ indicates the cost of normal disassembly and $C_{m}$ is the cost of destructive disassembly. For complex products, the coarse-grained evaluation of the target group is conducted, and then the total disassembly entropy of the target group is

$$
S=k_{1} S_{1}+k_{2} S_{2}+k_{3} S_{3}
$$

where $k_{\mathrm{i}}\left(i=1,2,3 ; k_{1}+k_{2}+k_{3}=1\right)$ is the weight of the disassembly entropy, and its value is determined by the degree of influence on the PDD feasibility of the target group. The total disassembly entropy of the target group fairly comprehensively reflects the overall feasibility evaluation of PDD for EOL products, and is the foundation of construct MGFEM of an EOL product.

\subsection{Fine-grained evaluation of component level}

\subsubsection{Construction of the fine-grained index of the component level}


A fine-grained evaluation object is a component. In the actual disassembly process, owing to the serious failure of the components, they cannot be disassembled, and the disassembly efficiency is improved by destroying some components. Therefore, the PDD feasibility is related to the failure degree and disassembly process of the components.

It is essential to recognize the PDD components and normal disassembly components during the PDD process. The PDD components should be low value or serious failure. Therefore, the more serious the failure characteristics are, the easier the identification of the failure disassembly components is and the better the PDD feasibility is. However, a serious component failure will lead to the increase of the required disassembly force and the difficulty of tool accessibility, which will seriously affect the efficiency of PDD. Moreover, the change of different disassembly tools and the relative positioning accuracy of the joints also seriously affect the efficiency of PDD. If the replacement of different disassembly tools occurs frequently, or there are the higher positioning accuracy requirements, these will increase the cost and energy consumption. Then, the PDD feasibility is worse. Furthermore, the larger the component structure size is, the more difficult it is for the PDD, because it will take more time to remove the corresponding connections and joints. Thus, eight fine-grained indexes, recognition of PDD components, disassembly tool, disassembly direction, disassembly time, pushing force, accessibility, positioning accuracy and component structure size were determined and shown in Fig. 1.

\subsubsection{Quantization of fine-grained index of the component level based on the failure characteristics}

The above indexes are related to the component failure degree, so the component fine-grained indexes were quantified based on the failure characteristics. In addition, the expert evaluation method was used to quantify the failure characteristics of components. Because the influence of the component failure characteristics on the fine-grained evaluation index is fuzzy, the fuzzy trigonometric function was integrated. The assessing scale set was used to grade the effect of the component failure degree on fine-grained indexes. The evaluation grade and value are shown in Table 2.

The different failure grades have different influences on the PDD feasibility. Moreover, the membership function of each index and failure grade was established according to the experts' experience and the literature [22-23], as shown in Fig. 2.

Taking the index of recognition of PDD components as an example (Fig. 2), according to the range of the failure characteristic value (Table 2), the membership of the interval $\left[\Delta a_{i}, \Delta a_{j}\right]$ is $\left[\Lambda_{i}^{a}, \Lambda_{j}^{a}\right]$, and the index of recognition of PDD components can be quantified as.

Table 2. The failure characteristics' influence level on fine-grained index

Fine-grained index Meaning

Description

Mark 


\begin{tabular}{|c|c|c|c|}
\hline \multirow[t]{4}{*}{$\begin{array}{l}\text { Recognition PDD } \\
\text { components }\end{array}$} & $\begin{array}{l}\text { Good to } \\
\text { recognize }\end{array}$ & $\begin{array}{l}\text { The failure characteristics of components are } \\
\text { obvious and good to recognize }\end{array}$ & $\Delta a_{1}$ \\
\hline & $\begin{array}{l}\text { Easy to } \\
\text { recognize }\end{array}$ & $\begin{array}{l}\text { The component failure feature is obvious and } \\
\text { easy to recognize }\end{array}$ & $\Delta a_{2}$ \\
\hline & $\begin{array}{l}\text { Difficult to } \\
\text { recognize } \\
\text { identification }\end{array}$ & $\begin{array}{l}\text { The component failure characteristics are not } \\
\text { obvious, so it is difficult to recognize }\end{array}$ & $\Delta a_{3}$ \\
\hline & $\begin{array}{l}\text { No } \\
\text { identification }\end{array}$ & No significant failure of components & $\Delta a_{4}$ \\
\hline \multirow[t]{2}{*}{ Disassembly tool } & $\begin{array}{l}\text { Does not need } \\
\text { to change }\end{array}$ & $\begin{array}{l}\text { Low degree of failure, high recovery value. Hand } \\
\text { or common tools required for normal } \\
\text { disassembly }\end{array}$ & $\Delta b_{0}$ \\
\hline & Need to change & $\begin{array}{l}\text { Low degree of failure, low recovery value. } \\
\text { Replace normal tools with destructive } \\
\text { disassembly tools }\end{array}$ & $\Delta b_{1}$ \\
\hline \multirow[t]{2}{*}{$\begin{array}{l}\text { Disassembly } \\
\text { direction }\end{array}$} & $\begin{array}{l}\text { Does not need } \\
\text { to change }\end{array}$ & $\begin{array}{l}\text { Low failure and high recovery value. Normal } \\
\text { disassembly of connectors without changing its } \\
\text { disassembly direction }\end{array}$ & $\Delta c_{0}$ \\
\hline & Need to change & $\begin{array}{l}\text { Low degree of failure, low recovery value. } \\
\text { Destroy connectors to change its disassembly } \\
\text { direction }\end{array}$ & $\Delta c_{1}$ \\
\hline \multirow[t]{2}{*}{ Disassembly time ${ }^{[22]}$} & $\begin{array}{l}\text { Does not need } \\
\text { to change }\end{array}$ & $\begin{array}{l}\text { General failure of component, take normal } \\
\text { disassembly, according to the original } \\
\text { disassembly time }\end{array}$ & $\Delta t_{0}$ \\
\hline & Need to change & $\begin{array}{l}\text { Serious failure of component; takes destructive } \\
\text { disassembly to reduce disassembly time }\end{array}$ & $\Delta t_{1}$ \\
\hline \multirow[t]{4}{*}{ Pushing force } & Great & $\begin{array}{l}\text { Serious failure of component, difficult to } \\
\text { dismantle; needs a greater force to overcome }\end{array}$ & $\Delta d_{1}$ \\
\hline & Moderation & $\begin{array}{l}\text { Medium failure of component, medium } \\
\text { disassembly force needed to overcome }\end{array}$ & $\Delta d_{2}$ \\
\hline & General & $\begin{array}{l}\text { Small failure of components requires general } \\
\text { disassembly force }\end{array}$ & $\Delta d_{3}$ \\
\hline & Small & $\begin{array}{l}\text { Not obvious failure component, only need to } \\
\text { overcome a small force }\end{array}$ & $\Delta d_{4}$ \\
\hline Accessibility & More difficult & $\begin{array}{l}\text { Component with a serious failure, resulting in } \\
\text { connector corrosion; challenging to remove } \\
\text { connector }\end{array}$ & $\Delta i_{1}$ \\
\hline
\end{tabular}




\begin{tabular}{|c|c|c|c|}
\hline & Hard & $\begin{array}{l}\text { Component's medium failure, resulting in } \\
\text { connector surface covered with rust; tool } \\
\text { contact with connector difficult }\end{array}$ & $\Delta i_{2}$ \\
\hline & General & Components generally fail, accessibility general & $\Delta i_{3}$ \\
\hline & Easy & $\begin{array}{l}\text { Component shows no failure, no visual } \\
\text { obstacles, connectors easily accessible to tools }\end{array}$ & $\Delta i_{4}$ \\
\hline \multirow[t]{4}{*}{ Positioning accuracy } & High & $\begin{array}{l}\text { The lower the degree of failure and the target } \\
\text { component, the higher the positioning accuracy } \\
\text { requirements }\end{array}$ & $\Delta g_{1}$ \\
\hline & Moderation & $\begin{array}{l}\text { Component failure degree is general, mainly } \\
\text { using normal disassembly, its positioning } \\
\text { accuracy requirements are medium }\end{array}$ & $\Delta g_{2}$ \\
\hline & General & $\begin{array}{l}\text { The failure degree of components is generally } \\
\text { medium, the damage and non-destructive } \\
\text { disassembly are combined, and the positioning } \\
\text { accuracy requirements are general }\end{array}$ & $\Delta g_{3}$ \\
\hline & $\begin{array}{l}\text { No precision } \\
\text { requirements }\end{array}$ & $\begin{array}{l}\text { Component failure is serious, take destructive } \\
\text { disassembly, its positioning accuracy is not } \\
\text { required }\end{array}$ & $\Delta g_{4}$ \\
\hline \multirow[t]{3}{*}{$\begin{array}{l}\text { Component } \\
\text { structure size }\end{array}$} & More difficult & $\begin{array}{l}\text { Component failure is serious and the structure is } \\
\text { large, so the tool is difficult to grasp }\end{array}$ & $\Delta k_{1}$ \\
\hline & General & $\begin{array}{l}\text { Components with general failure degree and } \\
\text { large structure, medium difficulty in grasping } \\
\text { tools }\end{array}$ & $\Delta k_{2}$ \\
\hline & Easy & $\begin{array}{l}\text { Components are basically non-failure and small } \\
\text { in structure, and tools are easy to grab }\end{array}$ & $\Delta k_{3}$ \\
\hline
\end{tabular}




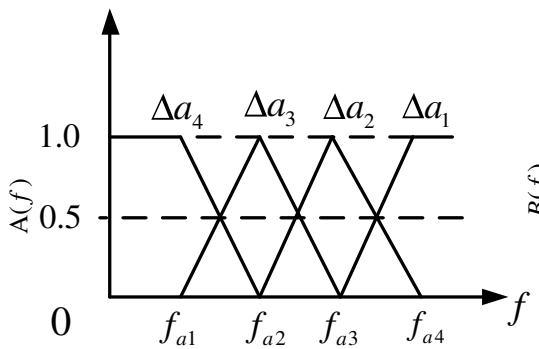

(a) Relationship between failure characteristics and recognition of PDD components

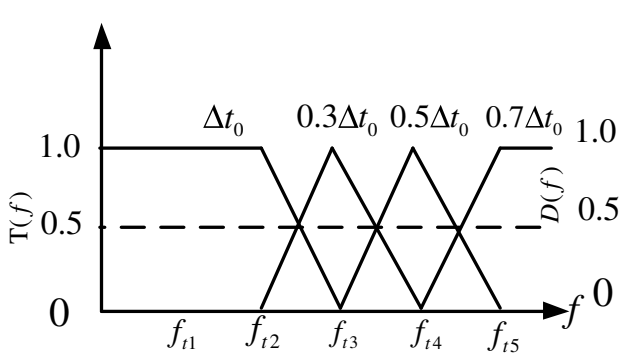

(d) Relationship between failure characteristics and disassembly time

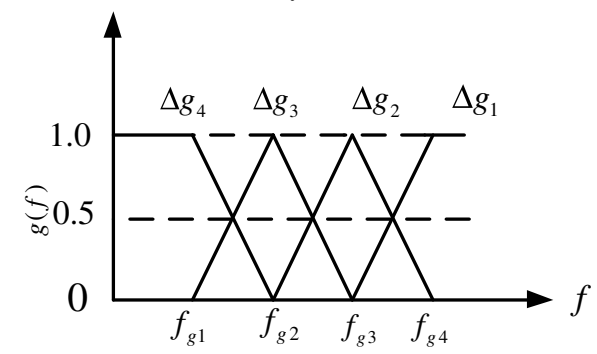

(g) Relationship between failure characteristics and positioning accuracy

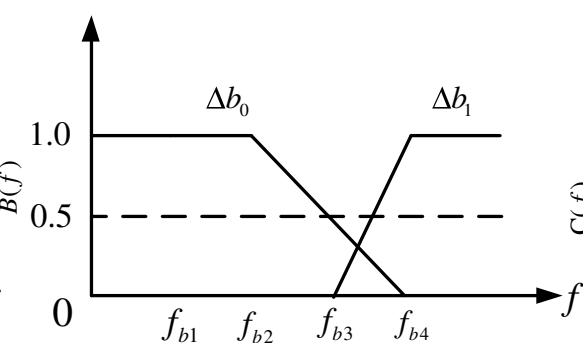

(b) Relationship between failure characteristics and disassembly tool

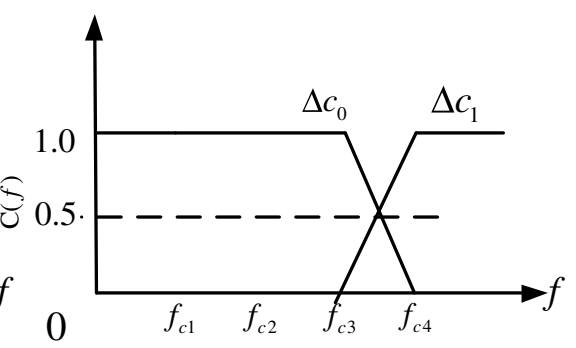

(c) Relationship between failure characteristics and disassembly direction

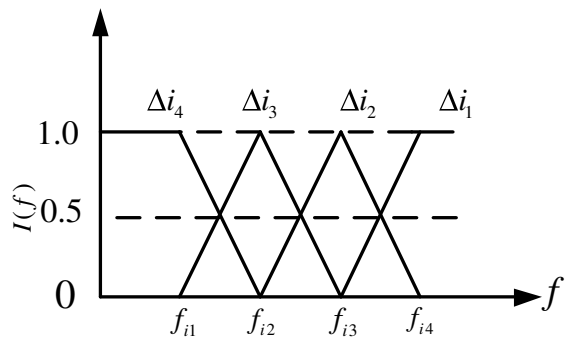

(e) Relationship between failure characteristics (f) Relationship between failure characteristics and and pushing force accessibility

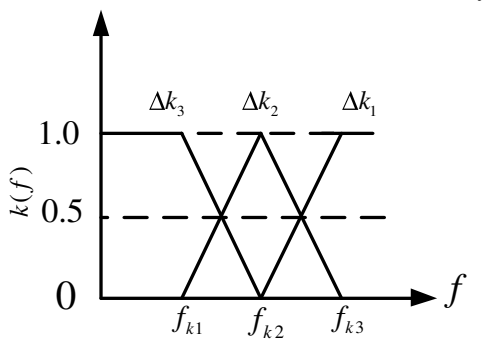

(h) Relationship between failure characteristics and component structure size

Figure 2. Fine-grained index membership function based on the failure characteristics

\subsubsection{Weight calculation based on structure entropy weight method}

To avoid the distortion of the evaluation results caused by the mutation value, we used the structural entropy weight method [24] to determine the weighting, and the specific steps are as follows.

Step 1. Certain experts are invited to rank the importance of each fine-grained indicator.

Step 2. The establishment of the fine-grained indicator set, collection of the expert opinions, and construction of the expert opinion matrix are denoted as follows:

$$
A=\left[\begin{array}{lll}
a_{11} & \cdots & a_{1 n} \\
\vdots & \ddots & \vdots \\
a_{k 1} & \cdots & a_{k n}
\end{array}\right],
$$

and the membership of the interval $\left[\Delta a_{i}, \Delta a_{j}\right]$ is $\left[\Lambda_{i}^{a}, \Lambda_{j}^{a}\right]$, 
where $a_{i j} i=1,2, \cdots, k ; j=1,2, \cdots, n \quad$ indicates the importance ranking of the $i$ th expert for item $j$ indicators. The membership of $a_{i j}$ is $b_{i j}$, where $b_{i j}$ is calculated according to the following formula:

$$
b_{i j}=-\frac{\ln m-a_{i j}}{\ln m-1},
$$

where $m$ is the number of transformation parameters [24], in this paper, letting $m=n+2$.

Determining that the

average awareness $b_{j}$ of $k$ experts on index $u_{j}$ is

$$
b_{j}=\frac{b_{1 j}+b_{2 j}+\cdots b_{k j}}{k}
$$

then, the blindness $Q_{j}[24]$ is

$$
\begin{gathered}
Q_{j}=\mid \frac{\left[\max b_{1 j}+b_{2 j}+\cdots b_{k j}-b_{j}\right]}{2}+ \\
\frac{\left[\min b_{1 j}+b_{2 j}+\cdots b_{k j}-b_{j}\right]}{2} \mid
\end{gathered}
$$

Then, the overall awareness $x_{i j}$ of $k$ experts on index $u_{j}$ is

$$
x_{j}=\left(1-b_{j}\right)\left(1-Q_{j}\right), x_{j}>0 .
$$

The evaluation vector of $k$ experts for indicators of the whole $U$ is

$$
X=\left[x_{1}, x_{2}, \cdots, x_{j}\right] .
$$

Step 3. According to Eq. (12), the weight of index $u_{j}$ is

$$
\alpha_{j}=x_{j} / \sum_{i=1}^{8} x_{j} .
$$

\subsubsection{Comprehensive evaluation of fine-grained indicators}

For components, a fine-grained evaluation of the component layer is performed, and then the fine-grained comprehensive evaluation result $T$ of the component layer is calculated according to the following Equation:

$$
T=\sum_{j=1}^{8} \alpha_{j} u_{j}
$$


where $\alpha_{j} j=1,2, \cdots, 8$ is the weight for each fine-grained index calculated by structural entropy weight method and $u_{j}$ is the fine-grained index.

\section{The comprehensive evaluation method}

In Section 2, the target group was used as the representative of the whole product level. If the coarse-grained disassembly entropy is less than a given threshold, it indicates that the PDD feasibility of the product is high. Then, the fine-grained evaluation of the component layer is needed to obtain the exact destructible disassembly components. The specific process is shown in Figure 3. The specific steps are as follows.

Step 1. Data (such as product failure information) are obtained according to the literature and practical experience.

Step 2. The product failure characteristic matrix is constructed, and the expert evaluation method is used to quantify the failure characteristics and calculate the eigenvalues.

Step 3. According to Section 2, the target group is selected according to the failure characteristics.

Step 4. According to Eqs. (4-6), the disassembly entropy of the failure rate and the disassembly entropy of the number of joints can be calculated. The total disassembly entropy of the target group can be calculated according to Eq. (7).

Step 5. Determine whether the total disassembly entropy $S$ is greater than the user-defined threshold; if it is greater, go to Step 6. Otherwise, go to Step 7.

Step 6. PDD is not feasible, so take normal disassembly.

Step 7. The fine-grained indexes are determined based on failure characteristics.

Step 8. Fuzzy triangular quantization of fine-grained indexes is performed based on failure characteristics. The structural entropy weight method is used to calculate the weight of each index and the fine-grained comprehensive evaluation value $T$ of components is calculated using Eq. (15).

Step 9. Sort the PDD components according to the comprehensive evaluation value in descending order. Thus, the disassembly priority of components is determined, and the results of the evaluation used as feedback to guide the PDD process. 


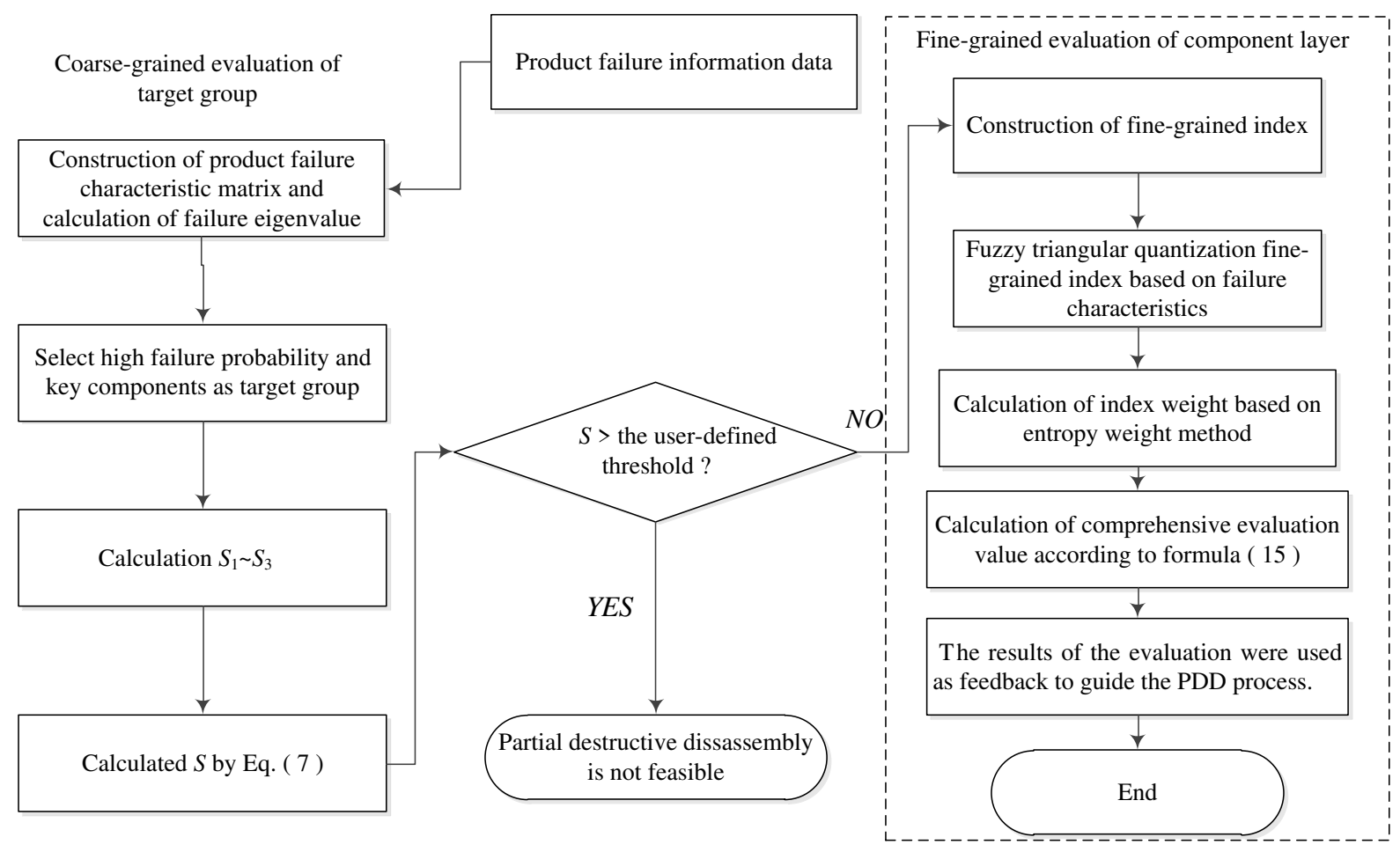

Figure 3. Flowchart of multi-granularity feasibility evaluation method for PDD

\section{Case study}

To verify the feasibility and effectiveness of this method, we used a Passat engine (Figure 4) as an example. Assuming that its failure information is known, the failure characteristic matrix of the product can be constructed according to Section 2 through human-computer interaction. Table 3 lists the main components and the related information of the engine.

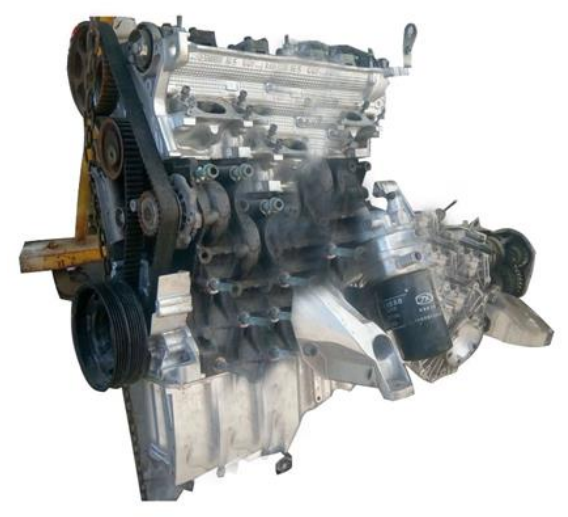

(a) Overall Structure of the Passat engine

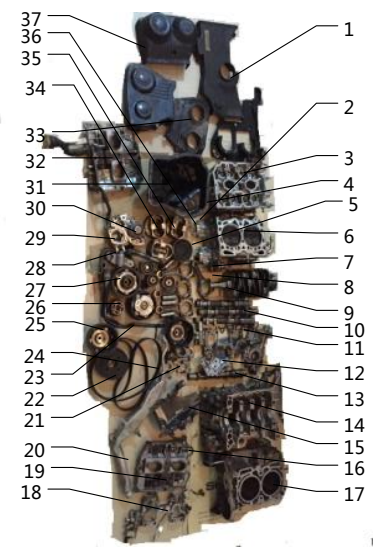

(b) After the engine is disassembled

Figure. 4. Overall structure and disassembly of a Passat engine

Table 3. Main parts information of Passat engine

$\begin{array}{llllll}\text { Part } & \text { Component name } & \text { Quanti } & \text { Remover } & \text { Disassembly } & \text { Connection type }\end{array}$




\begin{tabular}{|c|c|c|c|c|c|}
\hline number & & ty & & direction & (number) \\
\hline 1 & Train valve cover & 1 & Wrench & $+\mathrm{X}$ & Bolt connection (2) \\
\hline 2 & Booster pump wheel & 1 & Wrench & $+Y$ & Bolt connection (2) \\
\hline 3 & Oil pump & 1 & Screwdriver & $+X$ & Screw (2) \\
\hline 4 & Oil pump chain & 1 & Special tool & $+Z$ & Bolt connection (2) \\
\hline 5 & Turbocharger flywheel & 1 & Lama & $+Y$ & Welding \\
\hline 6 & Gearbox assembly & 1 & Wrench & $-Z$ & Bolt connection (2) \\
\hline 7 & Bearing shell & 8 & Hand & $+X /-X$ & Welding \\
\hline 8 & $\begin{array}{l}\text { Connecting rod bearing } \\
\text { shell }\end{array}$ & 8 & Hand & $+X /-X$ & Welding \\
\hline 9 & Cylinder & 1 & Screwdriver & $-X$ & Screw (2) \\
\hline 10 & Camshaft & 2 & Screwdriver & $+X$ & $\begin{array}{c}\text { Screw (2) and } \\
\text { geometric constraint }\end{array}$ \\
\hline 11 & Crankshaft & 1 & Hand & $+X$ & Geometric constraint \\
\hline 12 & Pitman & 4 & Wrench & $+X$ & Hexagonal nut (1) \\
\hline 13 & Igniter & 4 & Special tool & $+X$ & Bolt connection (8) \\
\hline 14 & Cylinder block & 4 & Hand & $+X$ & Welding \\
\hline 15 & $\begin{array}{l}\text { Air intake camshaft } \\
\text { Locking block }\end{array}$ & 5 & Screwdriver & $+X$ & Screw (2) \\
\hline 16 & $\begin{array}{l}\text { Exhaust camshaft locking } \\
\text { block }\end{array}$ & 5 & Screwdriver & $+X$ & Screw (2) \\
\hline 17 & Oil pan & 1 & Wrench & $-X$ & Bolt connection (2) \\
\hline 18 & Intake manifold & 1 & Wrench & $+Y$ & Hexagonal nut (1) \\
\hline 19 & Crankshaft bearing cap & 4 & Wrench & $+X$ & Bolt connection (2) \\
\hline 20 & Intake pipe & 2 & Screwdriver & $+Y$ & Screw (2) \\
\hline 21 & Booster belt & 1 & Special tool & $+Y$ & Geometric constraint \\
\hline 22 & Timing belt pulley & 1 & Lama & $+Z$ & Geometric constraint \\
\hline 23 & Exhaust manifold & 1 & Wrench & $-Y$ & Bolt connection (2) \\
\hline 24 & Timing belt & 1 & Special tool & $+Z$ & Elasticity \\
\hline 25 & Timing belt toothed & 1 & Lama & $+Z$ & Geometric constraint \\
\hline
\end{tabular}




$$
\text { pulley }
$$

\begin{tabular}{|c|c|c|c|c|c|}
\hline 26 & Crankshaft wheel & 1 & Lama & $+\mathrm{Z}$ & Geometric constraint \\
\hline 27 & $\begin{array}{c}\text { Camshaft transmission } \\
\text { wheel }\end{array}$ & 1 & Lama & $+Z$ & Geometric constraint \\
\hline 28 & Valve assembly & 1 & Wrench & $+X$ & Geometric constraint \\
\hline 29 & Air filter & 1 & Screwdriver & $+Y$ & Screw (2) \\
\hline 30 & $\begin{array}{l}\text { Booster belt tension } \\
\text { wheel }\end{array}$ & 1 & Lama & $+Y$ & Geometric constraint \\
\hline 31 & Engine support & 2 & Wrench & $+Y /-Y$ & Hexagonal nut (1) \\
\hline 32 & Turbocharger & 1 & Wrench & $+Y$ & Bolt connection (2) \\
\hline 33 & Connecting rod cap & 4 & Wrench & $+X$ & Bolt connection ( 2 ) \\
\hline 34 & Clutch flywheel & 1 & Hand & $-\mathrm{Z}$ & Geometric constraint \\
\hline 35 & Clutch pressure plate & 1 & Wrench & $-\mathrm{Z}$ & Hexagonal nut (1) \\
\hline 36 & Clutch driven plate & 1 & Hand & $-\mathrm{Z}$ & Geometric constraint \\
\hline 37 & Clutch cover back plate & 1 & Wrench & $-Z$ & Bolt connection (2) \\
\hline
\end{tabular}

The eigenvalue of engine parts failure is quantified according to Eq. (3), as shown in Eq. (16), and the target group is constructed according to Eq. (16); the information of the target group of the Passat engine is shown in Table 4.

$M_{2}=\left[\begin{array}{llllllllllllllllllll}1 & 4 & 7 & 8 & 9 & 10 & 11 & 12 & 13 & 14 & 15 & 16 & 17 & 18 & 20 & 21 & 24 & 27 & 29 & 34 \\ 0 & 0.27 & 0 & 0.31 & 0 & 0 & 0.48 & 0.65 & 0 & 0 & 0 & 0 & 0 & 0 & 0 & 0 & 0 & 0 & 0.78 & 0.27 \\ 0.92 & 0 & 0 & 0 & 0 & 0.38 & 0 & 0 & 0.28 & 0 & 0.68 & 0 & 0.75 & 0 & 0.8 & 0.9 & 0 & 0.26 & 0 & 0 \\ 0 & 0 & 0.28 & 0 & 0.36 & 0 & 0 & 0 & 0 & 0.27 & 0 & 0 & 0 & 0 & 0 & 0 & 0 & 0 & 0 & 0 \\ 0 & 0 & 0 & 0 & 0 & 0 & 0 & 0 & 0 & 0 & 0 & 0 & 0 & 0.86 & 0 & 0 & 0.84 & 0 & 0 & 0 \\ 0 & 0 & 0 & 0 & 0 & 0 & 0 & 0 & 0 & 0 & 0 & 0.65 & 0 & 0 & 0 & 0 & 0 & 0 & 0 & 0\end{array}\right] c_{1} .(1)$

Table 4. Information of target group of the Passat engine

\begin{tabular}{ccccccc}
\hline $\begin{array}{c}\text { Part } \\
\text { number }\end{array}$ & $\begin{array}{c}\text { Component } \\
\text { name }\end{array}$ & $\begin{array}{c}\text { Quant } \\
\text { ity }\end{array}$ & Remover & $\begin{array}{c}\text { Cost of } \\
\text { normal } \\
\text { disassembly } \\
(¥)^{[25]}\end{array}$ & $\begin{array}{c}\text { Joint type } \\
\text { (number) }\end{array}$ & $\begin{array}{c}\text { Cost of } \\
\text { destructive } \\
\text { disassembly } \\
(¥)^{[26]}\end{array}$ \\
\hline 1 & $\begin{array}{c}\text { Train valve } \\
\text { cover }\end{array}$ & 1 & Wrench & 0.31 & $\begin{array}{c}\text { Bolt } \\
\text { connection (2) }\end{array}$ & 0.2 \\
4 & Oil pump & 1 & Wrench & 0.37 & Bolt & 0.5 \\
\hline
\end{tabular}


chain

\begin{tabular}{|c|c|c|c|c|c|c|}
\hline 7 & Bearing shell & 8 & Hand & 0.76 & Welding & 0.32 \\
\hline & Connecting & & & 0.76 & & \\
\hline 8 & $\begin{array}{c}\text { rod bearing } \\
\text { shell }\end{array}$ & 8 & Hand & & Welding & 0.31 \\
\hline 9 & Cylinder & 8 & Hand & 3.76 & Screw (2) & 0.36 \\
\hline 10 & Camshaft & 2 & Screwdriver & 0.286 & $\begin{array}{l}\text { Screw (2) and } \\
\text { geometric } \\
\text { constraint }\end{array}$ & 0.38 \\
\hline 11 & Crankshaft & 1 & Hand & 0.84 & $\begin{array}{l}\text { Geometric } \\
\text { constraint }\end{array}$ & 0.24 \\
\hline 12 & Pitman & 4 & Wrench & 0.006 & $\begin{array}{l}\text { Hexagonal nut } \\
\text { (1) }\end{array}$ & 0.18 \\
\hline 13 & Igniter & 4 & Special tool & 0.17 & $\begin{array}{c}\text { Bolt } \\
\text { connection (8) }\end{array}$ & 0.4 \\
\hline 14 & $\begin{array}{l}\text { Cylinder } \\
\text { block }\end{array}$ & 4 & Hand & 0.17 & Welding & 0.18 \\
\hline 15 & $\begin{array}{c}\text { Air intake } \\
\text { Camshaft } \\
\text { locking block }\end{array}$ & 5 & Screwdriver & 0.36 & $\begin{array}{c}\text { Bolt } \\
\text { connection (2) }\end{array}$ & 0.3 \\
\hline 16 & $\begin{array}{c}\text { Exhaust } \\
\text { camshaft } \\
\text { Locking block }\end{array}$ & 5 & Screwdriver & 0.28 & $\begin{array}{c}\text { Bolt } \\
\text { connection (2) }\end{array}$ & 0.3 \\
\hline 17 & Oil pan & 1 & Wrench & 0.45 & $\begin{array}{c}\text { Bolt } \\
\text { connection (2) }\end{array}$ & 0.4 \\
\hline 18 & $\begin{array}{l}\text { Intake } \\
\text { manifold }\end{array}$ & 1 & Wrench & 0.17 & $\begin{array}{l}\text { Hexagonal nut } \\
\text { (1) }\end{array}$ & 0.2 \\
\hline 20 & Intake pipe & 2 & Screwdriver & 0.31 & Welding & 0.2 \\
\hline 21 & Booster belt & 1 & Special tool & 3.21 & $\begin{array}{l}\text { Geometric } \\
\text { Constraint }\end{array}$ & 0.18 \\
\hline 24 & Timing belt & 1 & Special tool & 3.19 & Elasticity & 0.28 \\
\hline 27 & $\begin{array}{c}\text { Camshaft } \\
\text { Transmission } \\
\text { Wheel }\end{array}$ & 1 & Lama & 0.84 & $\begin{array}{l}\text { Geometric } \\
\text { constraint }\end{array}$ & 0.29 \\
\hline 29 & Air filter & 1 & Screwdriver & 0.286 & Screw (2) & 0.2 \\
\hline
\end{tabular}




\begin{tabular}{ccccccc}
\hline 34 & $\begin{array}{c}\text { Clutch } \\
\text { flywheel }\end{array}$ & 1 & Hand & 0.6 & $\begin{array}{l}\text { Geometric } \\
\text { constraint }\end{array}$ & 0.29 \\
\hline
\end{tabular}

According to Table 4, letting $N_{i}=43, N_{s}=34, N_{k}=26, C_{n}=17.498$, and $C_{s}=0.43$, the disassembly entropies of the coarse-grained indexes of the target group are shown in Table 5.

Table 5. Evaluation results of the target group disassembly entropy of the Passat engine

\begin{tabular}{lccc}
\hline Coarse-grained index & Weight & Computation & $\begin{array}{l}\text { The coarse-grained } \\
\text { index of target } \\
\text { group }\end{array}$ \\
\hline Disassembly entropy of failure rate & 0.33 & 0.34 & 0.112 \\
Disassembly entropy of number of connector & 0.33 & 0.68 & 0.224 \\
Disassembly entropy of partial destructive cost & 0.34 & 0.43 & 0.146 \\
Total & 1 & - & 0.482 \\
\hline
\end{tabular}

The total disassembly entropy of the target group $S$ is obtained as 0.482 according to Table 5 , assuming that the user-defined threshold is 0.6 , and $S$ is less than the user-defined threshold. The smaller the disassembly entropy is, the better the PDD feasibility of the EOL products is, and then the fine-grained evaluation of the component level is needed to identify specific destructive disassembly components.

According to Fig. 2, the fine-grained index of PDD was quantified based on the component failure characteristics, which is shown in Table 6. Furthermore, the weight of the fine-grained index is determined by the structural entropy weight method, and the steps are shown in Table 7. According to Equation (15), the fine-grained comprehensive evaluation results of the engine components are shown in Table 8.

Table 6. Quantification of the engine's fine-grained index

\begin{tabular}{cccccccccc}
\hline Number & Component name & $T_{a}$ & $T_{b}$ & $T_{c}$ & $T_{t}$ & $T_{d}$ & $T_{g}$ & $T_{i}$ & $T_{k}$ \\
\hline 1 & Train valve cover & 0.87 & 1 & 1 & 3.2 & 1.24 & 0.575 & 1.093 & 0.97 \\
2 & $\begin{array}{c}\text { Booster pump } \\
\text { wheel }\end{array}$ & 0.027 & 0 & 0 & 1 & 0.12 & 0.12 & 0.1 & 0.192 \\
3 & Oil pump & 0.036 & 0 & 0 & 1 & 0.16 & 0.16 & 0.1 & 0.256 \\
4 & $\begin{array}{c}\text { Oil pump chain } \\
\text { Turbocharger } \\
5\end{array}$ & 0.06 & 0 & 0 & 1 & 0.27 & 0.27 & 0.135 & 0.34 \\
& flywheel & 0.053 & 0 & 0 & 1 & 0.24 & 0.24 & 0.12 & 0.384 \\
\hline
\end{tabular}




\begin{tabular}{|c|c|c|c|c|c|c|c|c|c|}
\hline 6 & Gearbox assembly & 0.051 & 0 & 0 & 1 & 0.23 & 0.23 & 0.115 & 0.368 \\
\hline 7 & Bearing shell & 0.062 & 0 & 0 & 1 & 0.28 & 0.28 & 0.14 & 0.36 \\
\hline 8 & $\begin{array}{l}\text { Connecting rod } \\
\text { bearing shell }\end{array}$ & 0.07 & 0 & 0 & 1 & 0.31 & 0.31 & 0.155 & 0.39 \\
\hline 9 & Cylinder & 0.08 & 0 & 0 & 1 & 0.36 & 0.36 & 0.18 & 0.46 \\
\hline 10 & Camshaft & 0.084 & 0 & 0 & 1 & 0.38 & 0.38 & 0.19 & 0.48 \\
\hline 11 & Crankshaft & 0.15 & 1 & 1 & 1 & 0.6 & 0.36 & 0.96 & 0.61 \\
\hline 12 & Pitman & 0.43 & 1 & 1 & 1.72 & 0.87 & 0.425 & 1.295 & 0.69 \\
\hline 13 & Igniter & 0.062 & 0 & 0 & 1 & 0.28 & 0.28 & 0.14 & 0.36 \\
\hline 14 & Cylinder block & 0.06 & 0 & 0 & 1 & 0.27 & 0.27 & 0.135 & 0.34 \\
\hline 15 & $\begin{array}{l}\text { Air intake camshaft } \\
\text { Locking block }\end{array}$ & 0.48 & 1 & 1 & 1.92 & 0.91 & 0.44 & 0.83 & 0.72 \\
\hline 16 & $\begin{array}{c}\text { Exhaust camshaft } \\
\text { locking block }\end{array}$ & 0.43 & 1 & 1 & 1.72 & 0.87 & 0.425 & 1.295 & 0.69 \\
\hline 17 & Oil pan & 0.6 & 1 & 1 & 2.4 & 1 & 0.475 & 0.9 & 0.79 \\
\hline 18 & Intake manifold & 0.78 & 1 & 1 & 3.2 & 1.18 & 0.538 & 1.021 & 0.91 \\
\hline 19 & $\begin{array}{c}\text { Crankshaft bearing } \\
\text { cap }\end{array}$ & 0.051 & 0 & 0 & 1 & 0.23 & 0.23 & 0.115 & 0.368 \\
\hline 20 & Intake pipe & 0.68 & 1 & 1 & 3.2 & 1.1 & 0.5 & 0.95 & 0.84 \\
\hline 21 & Booster belt & 0.85 & 1 & 1 & 3.2 & 1.23 & 0.562 & 1.069 & 0.95 \\
\hline 22 & Timing belt pulley & 0.051 & 0 & 0 & 1 & 0.23 & 0.23 & 0.115 & 0.368 \\
\hline 23 & Exhaust manifold & 0.051 & 0 & 0 & 1 & 0.23 & 0.23 & 0.115 & 0.368 \\
\hline 24 & Timing belt & 0.78 & 1 & 1 & 3.2 & 1.15 & 0.525 & 0.998 & 0.88 \\
\hline 25 & $\begin{array}{l}\text { Timing belt } \\
\text { toothed pulley }\end{array}$ & 0.051 & 0 & 0 & 1 & 0.23 & 0.23 & 0.115 & 0.368 \\
\hline 26 & Crankshaft wheel & 0.051 & 0 & 0 & 1 & 0.23 & 0.23 & 0.115 & 0.368 \\
\hline 27 & $\begin{array}{c}\text { Camshaft } \\
\text { transmission wheel }\end{array}$ & 0.058 & 0 & 0 & 1 & 0.26 & 0.26 & 0.13 & 0.33 \\
\hline 28 & Valve assembly & 0.051 & 0 & 0 & 1 & 0.23 & 0.23 & 0.115 & 0.368 \\
\hline 29 & Air filter & 0.65 & 1 & 1 & 3.12 & 1.04 & 0.49 & 0.93 & 0.82 \\
\hline
\end{tabular}




\begin{tabular}{lccccccccc}
\hline 30 & $\begin{array}{c}\text { Booster belt } \\
\text { tension wheel }\end{array}$ & 0.051 & 0 & 0 & 1 & 0.23 & 0.23 & 0.115 & 0.368 \\
31 & Engine support & 0.051 & 0 & 0 & 1 & 0.23 & 0.23 & 0.115 & 0.368 \\
32 & Turbocharger & 0.051 & 0 & 0 & 1 & 0.23 & 0.23 & 0.115 & 0.368 \\
33 & Connecting rod cap & 0.051 & 0 & 0 & 1 & 0.23 & 0.23 & 0.115 & 0.368 \\
34 & $\begin{array}{c}\text { Clutch flywheel } \\
\text { Clutch pressure }\end{array}$ & 0.06 & 0 & 0 & 1 & 0.27 & 0.27 & 0.135 & 0.34 \\
35 & $\begin{array}{c}\text { plate } \\
36\end{array}$ & 0.051 & 0 & 0 & 1 & 0.23 & 0.23 & 0.115 & 0.368 \\
37 & $\begin{array}{c}\text { Clutch driven plate } \\
\text { Clutch cover back } \\
\text { plate }\end{array}$ & 0.053 & 0 & 0 & 1 & 0.24 & 0.24 & 0.12 & 0.384 \\
& 0.027 & 0 & 0 & 1 & 0.12 & 0.12 & 0.1 & 0.192 \\
\hline
\end{tabular}

Table 7. Weight determination step based on the structure entropy weight method

\begin{tabular}{ccccccccc}
\hline Calculation & $T_{a}$ & $T_{b}$ & $T_{c}$ & $T_{t}$ & $T_{d}$ & $T_{g}$ & $T_{i}$ & $T_{k}$ \\
\hline Group 1 & 1 & 2 & 3 & 4 & 5 & 6 & 7 & 8 \\
Group 2 & 1 & 2 & 4 & 3 & 7 & 8 & 5 & 6 \\
Group 3 & 2 & 1 & 3 & 4 & 6 & 7 & 5 & 8 \\
$b_{j}$ & 0.9821 & 0.9643 & 0.8622 & 0.8389 & 0.6211 & 0.4821 & 0.655 & 0.4206 \\
$b_{i j}(\max )$ & 1 & 1 & 0.8856 & 0.8856 & 0.7325 & 0.6309 & 0.7325 & 0.6309 \\
$1-Q_{j}$ & 0.9911 & 0.9911 & 0.98835 & 0.98835 & 0.8471 & 0.9911 & 0.96125 & 0.9474 \\
$x_{j}$ & 0.0178 & 0.0354 & 0.1362 & 0.1592 & 0.3210 & 0.5133 & 0.3316 & 0.5490 \\
$\alpha_{j}$ & 0.0086 & 0.017 & 0.0660 & 0.0772 & 0.1556 & 0.2488 & 0.1607 & 0.2661 \\
\hline
\end{tabular}

Table 8. Fine-grained comprehensive evaluation result of the engine components

\begin{tabular}{ccc}
\hline Part number & Component name & $\begin{array}{c}\text { Comprehensive assessment } \\
\text { value }\end{array}$ \\
\hline 1 & Train valve cover & 1.1073 \\
21 & Booster belt & 1.0931 \\
18 & Intake manifold & 1.0604 \\
\hline
\end{tabular}




\begin{tabular}{|c|c|c|}
\hline 24 & Timing belt & 1.0407 \\
\hline 20 & Intake pipe & 1.0076 \\
\hline 29 & Air filter & 0.9808 \\
\hline 17 & Oil pan & 0.9021 \\
\hline 15 & Air intake camshaft locking block & 0.8114 \\
\hline 12 & Pitman & 0.6979 \\
\hline 16 & Exhaust camshaft locking block & 0.6979 \\
\hline 11 & Crankshaft & 0.5448 \\
\hline 10 & Camshaft & 0.4069 \\
\hline 9 & Cylinder & 0.3918 \\
\hline 8 & Connecting rod bearing shell & 0.3489 \\
\hline 7 & Bearing shell & 0.3263 \\
\hline 13 & Igniter & 0.3263 \\
\hline 4 & Oil pump chain & 0.3161 \\
\hline 14 & Cylinder block & 0.3161 \\
\hline 34 & Clutch flywheel & 0.3161 \\
\hline 27 & Camshaft transmission wheel & 0.3132 \\
\hline 5 & Turbocharger flywheel & 0.3132 \\
\hline 36 & Clutch driven plate & 0.3085 \\
\hline 6 & Gearbox assembly & 0.3041 \\
\hline 19 & Crankshaft bearing cap & 0.3041 \\
\hline 22 & Timing belt pulley & 0.3041 \\
\hline 23 & Exhaust manifold & 0.3041 \\
\hline 25 & Timing belt toothed pulley & 0.3041 \\
\hline 26 & Crankshaft wheel & 0.3041 \\
\hline 28 & Valve assembly & 0.3041 \\
\hline 30 & Booster belt tension wheel & 0.3041 \\
\hline
\end{tabular}




\begin{tabular}{ccc}
\hline 31 & Engine support frame & 0.3041 \\
32 & Turbocharger & 0.3041 \\
33 & Connecting rod cap & 0.3041 \\
35 & Clutch pressure plate & 0.3041 \\
3 & Oil pump & 0.2434 \\
2 & Booster pump wheel & 0.2101 \\
37 & Clutch cover back plate & 0.2101 \\
\hline
\end{tabular}

As shown in Table 8, the PDD of the engine is feasible, and the comprehensive score of the train valve cover is the highest, which should be disassembled preferentially. The train valve cover is to cover and seal the cylinder head, and isolate pollutants, such as dirt and humidity from the outside. Therefore, it is in a bad environment for a long time, which can result in a serious failure. In engineering practice, destructive disassembly is preferred owing to its low remanufacturing value and possibility of serious failure, which is consistent with the above evaluation result.

\section{Conclusions}

This paper proposes a multi-granularity feasibility evaluation method for EOL products to judge the PDD feasibility from the product level to the component level based on the disassembly entropies and the product's failure characteristic. The highlights of the proposed method are as follows.

(1) The multi-granularity feasibility evaluation method proposed in this paper is an effective process. The coarse-grained evaluation of the whole product is performed first. If the total disassembly entropy of the target group is greater than the user-defined threshold, the following fine-grained evaluation is unnecessary, which reduces the blindness of the evaluation and improves the evaluation efficiency.

(2) The target group is constructed based on the failure characteristics of product components to simplify the overall evaluation difficulty of PDD for EOL product, which can provide technical support for the PDD feasibility evaluation of large complex products.

(3) The fine-grained index of PDD was determined and quantified based on the failure characteristics and the fuzzy membership function, which solves the fuzzy effect of product failure on PDD and greatly improves the efficiency in the feasibility evaluation of PDD process.

However, in the construction of the target group, only the high failure probability and key components were considered, and the failure characteristic information of components was difficult to obtain. Software should be developed to perform the extraction of the failure characteristics of an EOL product automatically to increase the evaluation efficiency in the follow-up work. 


\section{Ethical Approval}

All analyses were based on previous published studies, thus no ethical approval and patient consent are required.

\section{Consent to Participate}

Not applicable

\section{Consent to Publish}

A statement under the 'Consent to publish' heading confirming that you have obtained consent to publish from the participant (or legal parent or guardian for children) to report individual patient data. Note this is required where an article reports an individual participant's data in any form (including images, videos, voice recordings etc.

\section{Authors Contributions}

Conceptualization, L.G. and X.Z.; methodology, L.G.; validation, L.G. and X.Z.; formal analysis, L.G.; investigation, L.G. and X.Z.; resources, L.G. and X.Z.; data curation, L.G.; writing-original draft preparation, L.G.; writing-review and editing, L.G.; visualization, L.G. and X.Z.; supervision, L.G.; project administration, X.Z.; funding acquisition, X.Z. All authors have read and agreed to the published version of the manuscript.

\section{Funding}

This article is supported by the National Natural Science Foundation of China (No.51965049) and the Program for Young Talents of Science and Technology in Universities of Inner Mongolia Autonomous Region (NJYT-17-B08).

\section{Competing Interests}

The authors have declared that no competing interests exist

\section{Availability of data and materials}

The datasets used or analysed during the current study are available from the corresponding author on reasonable request.

\section{Acknowledgments}

We thank LetPub (www.letpub.com) for its linguistic assistance during the preparation of this manuscript. This article is supported by the National Natural Science Foundation of China (No.51965049) and the Program for Young Talents of Science and Technology in Universities of Inner Mongolia Autonomous Region (NJYT-17-B08). 


\section{References}

[1] Yao JK, Yang JE, Zhu S (2006). Quality control in remanufacturing waste product. China Surface Engineering 19(1): 115-117.

[2] Li JR, Xia K, Gao L (2013). Selective disassembly planning of waste electrical and electronic equipment with case studies on liquid crystal displays. Robotics and Computer-Integrated Manufacturing 29(4):248-301.

[3] Tian YT, Zhang XF, Liu ZH (2019). Product cooperative disassembly sequence and task planning based on genetic algorithm. The International Journal of Advanced Manufacturing Technology 105(5-6):2103-2120.

[4] Zhang XF, Zhang SY (2010). Product cooperative disassembly sequence planning based on branch-and-bound algorithm. International Journal of Advanced Manufacturing Technology 51(9-12):1139-1147.

[5] Song XW, Pan XX, Zhou WD (2013). Complex product disassembly sequence planning oriented to defective parts. Computer Integrated Manufacturing Systems 19(06):1249-1255.

[6] Tseng HE, Huang YM, Chang CC (2020). Disassembly sequence planning using a Flatworm algorithm. Journal of Manufacturing Systems 57:416-428.

[7] Umeda Y, Miyaji N, Shiraishi Y(2015). Proposal of a design method for semi-destructive disassembly with split lines. CIRP Annals-manufacturing Technology, 64(1):29-32.

[8] DU YB, Cao HJ, Liu F (2012). An integrated method for evaluating the remanufacturability of used machine tool. Journal of Cleaner Production 20(1):82-91.

[9] Suga T, Hosoda N (1997). A Consideration on the Quantitative Disassembly Evaluation. Journal of Japan Institute of Electronics Packaging 12(1):34-40.

[10] Aguiar J, Oliverira, Silva J (2017). A design tool to diagnose product recyclability during product design phase. Journal of Cleaner Production 141(10):219-229.

[11] Header A, Bubnish K (2019). Automated contact and non-contact constraint generation for disassembly feasibility and planning. Procedia CIRP80 (1):548-553.

[12] Achillas C, Michailidis N (2009). A methodological framework for end-of-life management of electronic products. Resources Conservation and Recycling 53(6):329-339.

[13]Chen ZW, Xu HX (2003). Research on the evaluation index of disassembly ability for disassembly design. Manufacturing Automation 25(007):22-24.

[14] Sun YC, Huang JY, Wang W (2010). Quantitative Evaluation Method of Product Disassembly Based on Parts Failure Rate and Disassembly Time. Journal of Mechanical Engineering 46(13):147-154.

[15]Song XW, Zhou WD, Pan XX (2013). Disassembly sequence planning for electromechanical product under a partial destructive mode. Assembly Automation 34 (1): 106-114. 
[16]Zeng YQ, Zhang ZQ, Liu JQ (2020). Modeling and Optimization of Partial Destructive Disassembly-line Balancing Problem. Information and Control 49(03):365-376.

[17]Wang K, Gao L, Li XY (2020). A multi-objective algorithm for U-shaped disassembly line balancing with partial destructive mode. Neural Computig and Application 32(11):1-22.

[18]Zhang XF, Zhang SY, Yi GD (2010). Multi-granularity and hierarchy disassemblability evaluation model and methodology for products. Journal of Zhejiang University (Engineering Science) 44(3):581-588.

[19]Zhu WM, Fan XM He QC (2020). A hierarchical and process-oriented framework for disassemblability evaluation in product maintainability design. International Journal of Advanced Manufacturing Technology 110(3-4):777-795.

[20]Coulibaly A, Houssin R, Mutel B (2007). Maintainability and safety indicators at design stage for mechanical products.Computers in Industry 59(5):438-449.

[21] Suga T, Hosoda N (2000). Active Disassembly and Reversible Interconnection. IEEE International Symposium on Electronics and the Environment.

[22] Yang DY, Xu ZG, Zhu JF (2019). Objective selective disassembly sequence planning considered product fault features. Journal of Harbin Institute of Technology 51(07):160-170.

[23] Du YB, Liao L (2015). Remanufacturability evaluation method of mechanical parts based on failure features.Computer Integrated Manufacturing Systems 21(01): 135-142.

[24]Cheng QY (2010). Structure entropy weight method to confirm the weight of evaluating index. Systems Engineering-Theory \& Practice 30(07):1225- 1228.

[25]Zeng QY(2014). Research on purchasing target cost management of engine parts of $G$ Company. Guangzhou: South China University of Technology.

[26] Pan XX (2012). Research on electromechanical product disassembly sequence planning based on partial destruction mode. Hangzhou: Zhejiang University. 


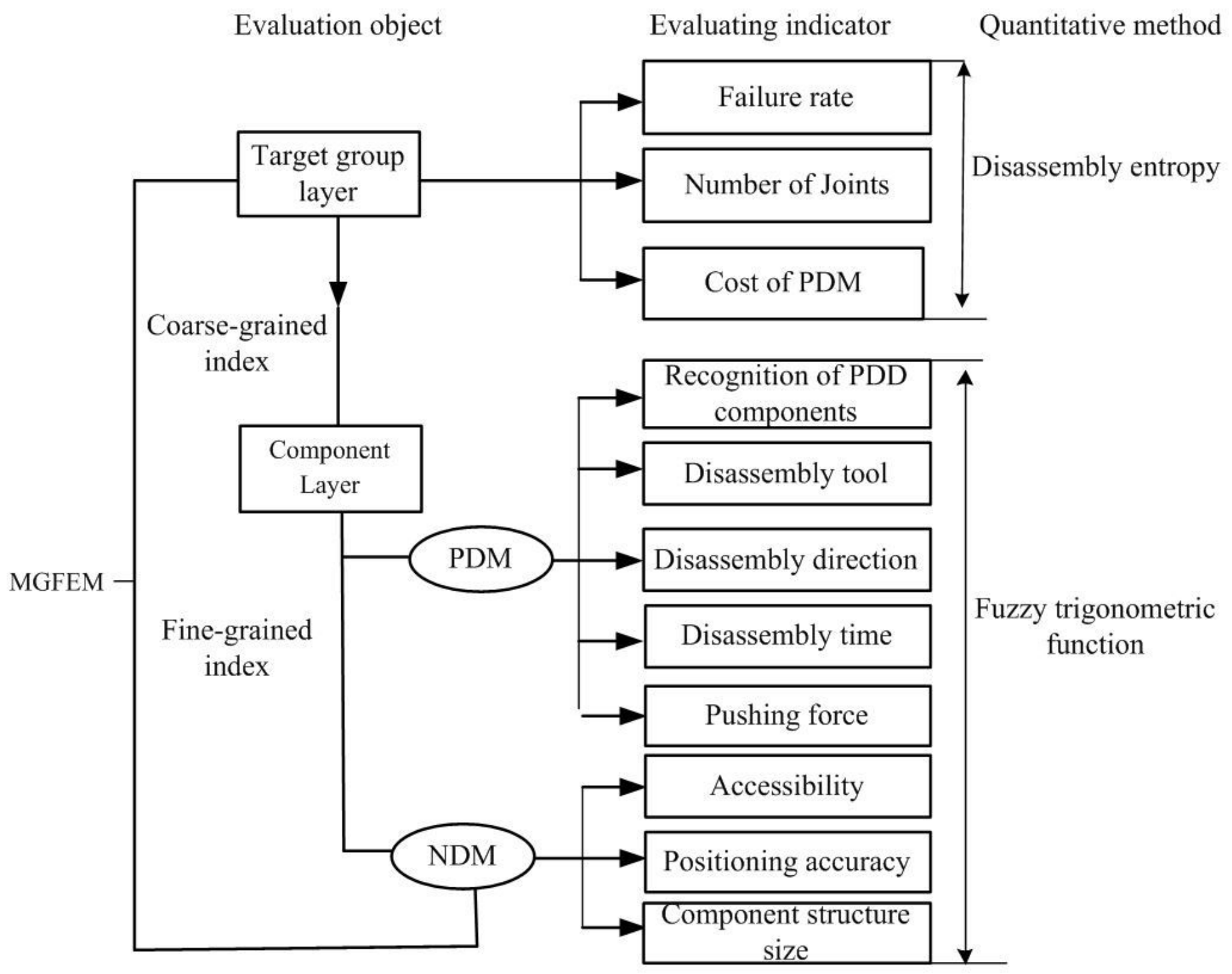

Figure 1

MGFEM of the PDD for an EOL product 


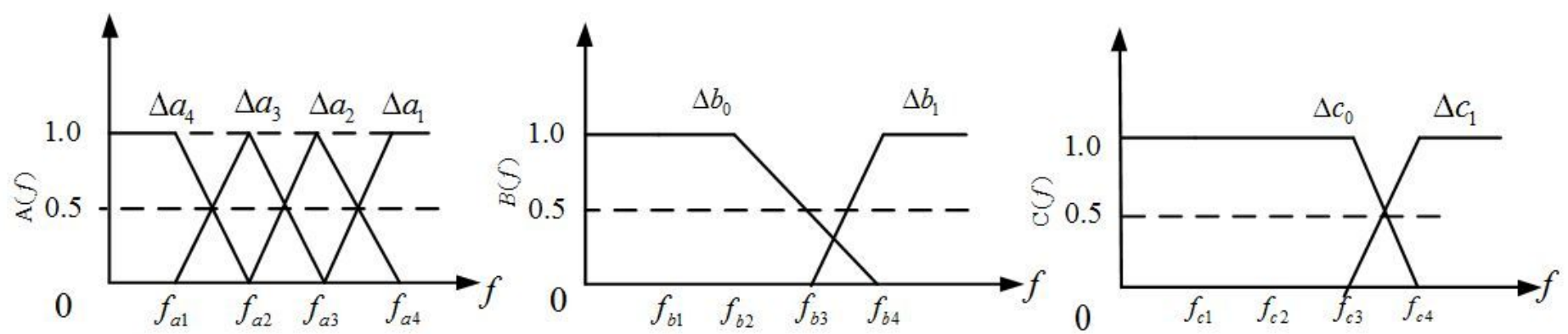

(a) Relationship between failure characteristics (b) Relationship between failure characteristics and recognition of PDD components and disassembly tool

(c) Relationship between failure characteristics and disassembly direction
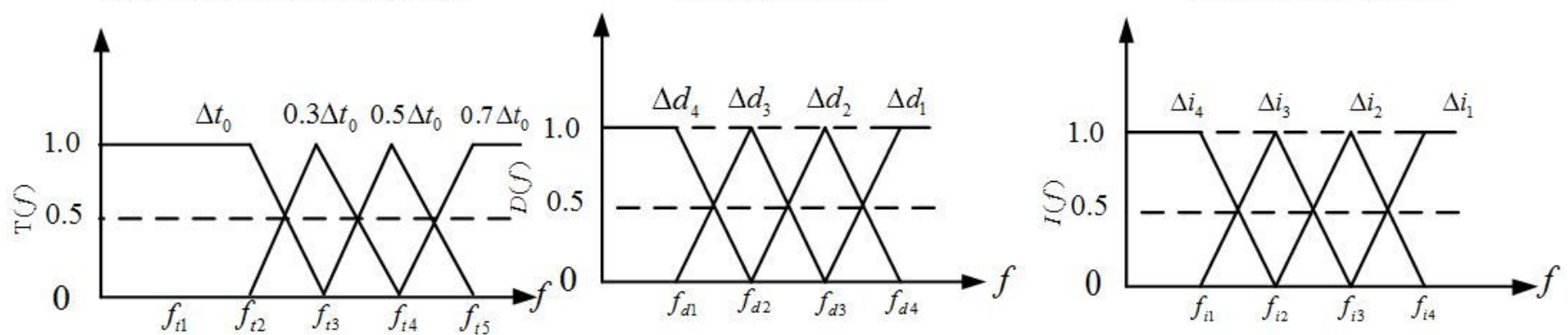

(d) Relationship between failure characteristics and disassembly time

(e) Relationship between failure characteristics (f) Relationship between failure characteristics and and pushing force accessibility

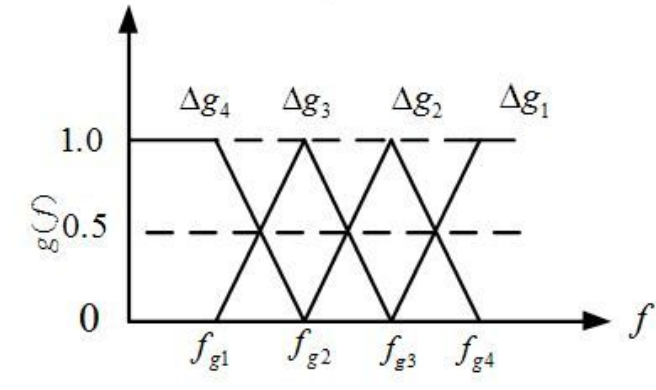

(g) Relationship between failure characteristics and positioning accuracy

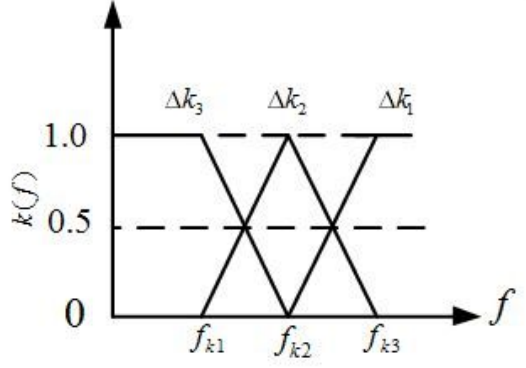

(h) Relationship between failure characteristics and component structure size

Figure 2

Fine-grained index membership function based on the failure characteristics 


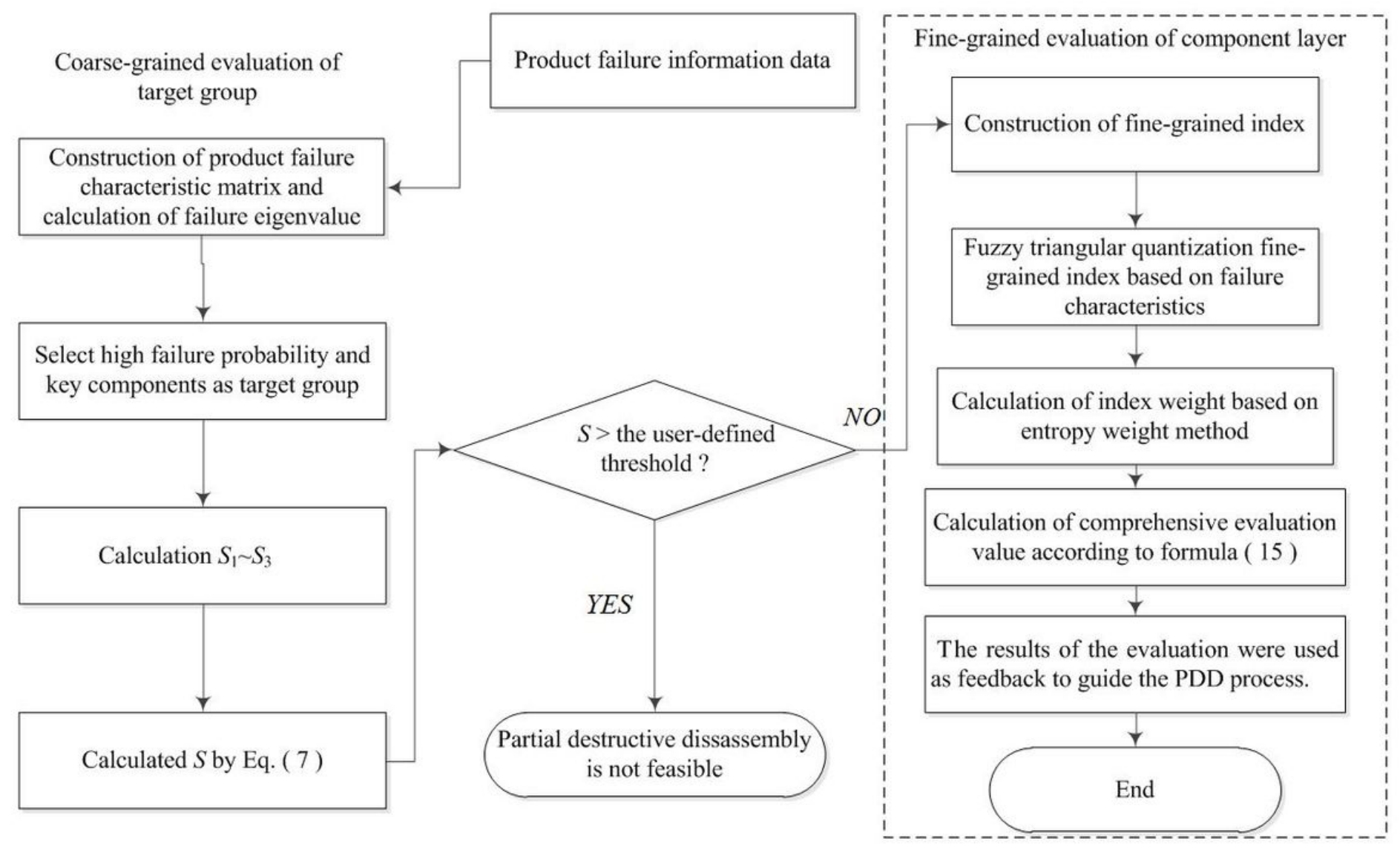

Figure 3

Flowchart of multi-granularity feasibility evaluation method for PDD

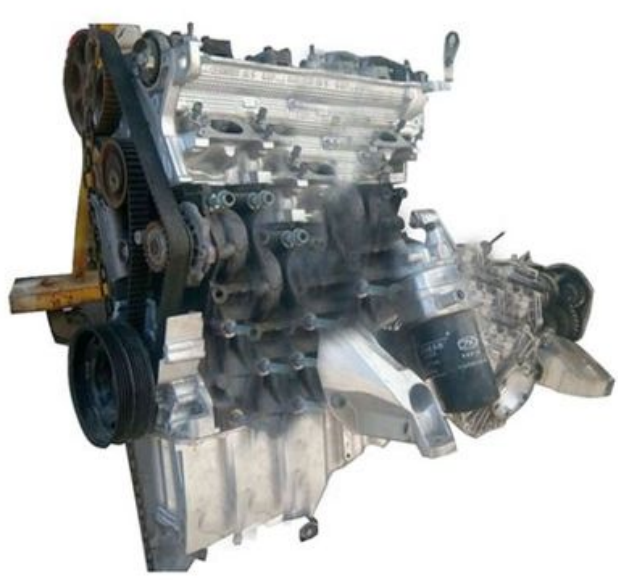

(a) Overall Structure of the Passat engine

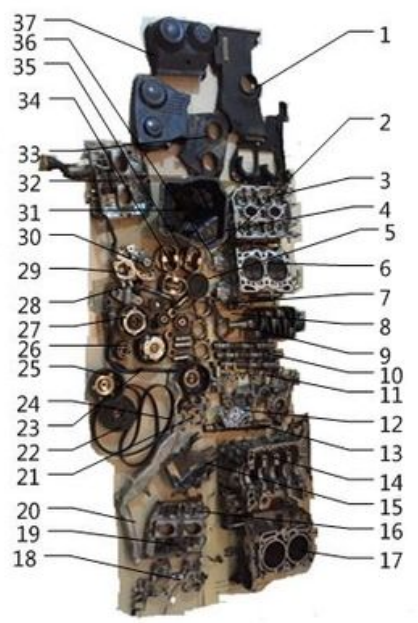

(b) After the engine is disassembled

\section{Figure 4}

